\title{
MODELING OF HYDRODYNAMICS AND COHESIVE SEDIMENT PROCESSES IN AN ESTUARINE SYSTEM: STUDY CASE IN \\ DANSHUI RIVER
}

Short title: HYDRODYNAMICS AND SEDIMENT PROCESSES IN DANSHUI RIVER

\author{
A. ETEMAD-SHAHIDI
}

School of Civil Eng., Iran University of Science and Technology, Tehran, Iran, P.O. BOX 16765-163, Telfax: 9821 77240399, etemad@iust.ac.ir

\section{A. SHAHKOLAHI}

School of Civil Eng., Iran University of Science and Technology, Tehran, Iran, P.O. BOX $16765-163$

\section{WEN-CHENG LIU}

Department of Civil and Disaster Prevention Engineering, National United University, Miao-Li 36003, Taiwan, wcliu@ nuu.edu.tw

\begin{abstract}
Danshui River estuarine system is the largest estuarine system in northern Taiwan and is formed by the confluence of Tahan Stream, Hsintien Stream and Keelung River. A comprehensive one-dimensional model was used to model hydrodynamics and cohesive sediment transport in this branched River estuarine system. The applied unsteady model uses advection/dispersion equation to model the cohesive sediment transport. The erosion
\end{abstract}


and deposition processes are modeled as source/sink terms. The equations are solved numerically using an implicit finite difference scheme. Water surface elevation and longitudinal velocity time series were used to calibrate and verify the hydrodynamics of the system. To calibrate and verify the mixing process, the salinity time series was used and the dispersion coefficient of the advection/dispersion equation was determined. The cohesive sediment module was calibrated by comparing the simulated and field measured sediment concentration data and the erosion coefficient of the system was determined. A minimum mean absolute error of $4.22 \mathrm{mg} / \mathrm{L}$ was obtained and the snapshots of model results and field measurements showed a reasonable agreement. Our modeling showed that a 1-Dimensional model is capable of simulating the hydrodynamics and sediment processes in this estuary and the sediment concentration has a local maximum at the limit of salinity intrusion. Furthermore, it was indicated that for $Q_{50}$ (the flow which is equaled or exceeded $50 \%$ times), the turbidity maximum location during neap tide is about $1 \mathrm{~km}$ closer to the mouth compared to that during spring tide. It was found that deposition is the dominant sediment transport process in the river during spring-neap periods. It was shown that while sediment concentration at the upstream depends on the river discharge, the concentration in the downstream is not a function of river discharge.

Keywords: numerical simulation; Danshui River; Mike 11; estuarine hydrodynamic; sediment transport

\section{INTRODUCTION}

Cohesive sediment transport in estuaries can lead to occurrence of siltation in waterways and erosion of estuarine banks. However, cohesive sediments move as suspended materials 
and have an important role in water quality. Suspended sediments have a major role on both the primary production and pollutant transport in coastal systems. Therefore, it is an important factor in the quality of coastal waters $[12,48,40]$. Estuarine fine sediments make both positive and negative contributions to the coastal environment and present significant challenges for sustainable management of water resources. Considering the economical and environmental importance of cohesive sediment transport, accurate simulation of cohesive sediment transport processes in estuarine and coastal waters are necessary for environmental management, dredging studies, damming projects and even global sea level rise [33]. Therefore, considerable effort has been put into the modeling and simulation of hydrodynamic and cohesive sediment transport. Erosion, deposition and flocculation processes, and tidal asymmetry make the simulation of the sediment transport process a difficult task $[47,38,51]$. In order to achieve this, the dynamics of the major forcings, i.e., tidal amplitude and river discharge as well as salinity distribution should be characterized.

Numerical models of cohesive sediment transport are extensions of numerical hydrodynamic models. All the current cohesive sediment transport models use an advection-dispersion equation to simulate the transport of sediments. This equation requires current velocity components that are normally obtained from a hydrodynamic model. The utilized hydrodynamic models can be classified based on their dimensionality, i.e., 1Dimensional, 2-Dimensional and 3-Dimensional. For example, Scarlatos [42], Lin et al. [26] and Neary et al. [37] used 1-D models to study the cohesive sediment transport while 2-D dimensional models have been applied by Hayter and Mehta [20], Cole and Miles [8], Falconer and Chen [13], Burchard and Baumert [3], Van Wijngaarden [53], Liu et al. [30], Lumborg and Windelin [33], and Rao et al. [41]. More recently and with the increase of the 
computational power, 3-Dimensional models are also used for modeling of hydrodynamics and cohesive sediment transport in natural water bodies [e.g. 2, 4, 19, 24, 25, 19, 56]. However, Neary et al. [37] showed that one-dimensional modeling of cohesive sediment transport may offer a practical and cost-effective alternative compared to fully 2-D and 3-D models, with relatively less model set-up and run-time requirements.

The cohesive sediment transport is based on more uncertain physical principles than hydrodynamics. Hence, a number of cohesive sediment erosion, flocculation, and deposition equations are usually incorporated in the sediment transport module of numerical models [e.g. 16, 24, 35]. Liu et al. [30, 31, 32] and Liu [28] applied a vertical two-dimensional model to simulate water surface elevation, current, salinity, mixing processes, and cohesive sediment concentration in the Danshui River estuarine system. The aim of this paper is to study the effect of river discharge on the sediment transport processes using a 1-D model. Hence, a numerical model called MIKE 11 [10] is used for modeling the hydrodynamics and cohesive sediment transport processes in the Danshui River estuarine system. This paper describes the fundamentals of modeling of the hydrodynamics and cohesive sediment transport processes in this multi-branched estuarine system.

\section{STUDY AREA}

The Danshui River estuarine system is formed by the confluence of the Tahan Stream, Hsintien Stream, and Keelung River (Figure 1). The downstream portions of all three tributaries are influenced by tide and subjected to seawater intrusion. Together, they form the largest estuarine system in Taiwan with its drainage basin including the capital city of 
Taipei. The system has a total drainage area of $2726 \mathrm{~km}^{2}$, about $7.6 \%$ of the total area of Taiwan. The primary soils are Entisol and Inceptisol according to Soil Taxonomy [44]. The underlying geology is dominated by argillite and slate with sandstone interbeds formed after the Oligocence [21]. Montane forest covers about $93 \%$ of the watershed land area, agricultural land use comprises $5 \%$, and $<1 \%$ belongs to residential areas and other manmade constructions, including roads.

The length of the main stem is $159 \mathrm{~km}$. The headlands of the watershed reach a maximum altitude of $3529 \mathrm{~m}$. The area with altitude less than $250 \mathrm{~m}$ comprises approximately $1 / 3$ of the total area; the flat area with altitude less than $20 \mathrm{~m}$ in the Taipei Basin is only $243 \mathrm{~km}^{2}$. The mean river discharges are $62.1,72.7$ and $26.1 \mathrm{~m}^{3} / \mathrm{s}$ in the Tahan Stream, Hsintien Stream and Keelung River, respectively. The total solid matters

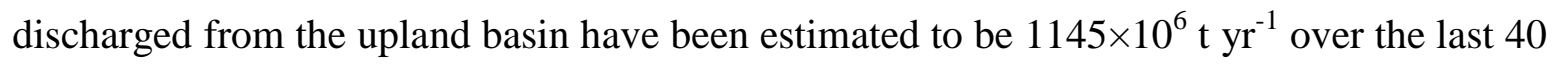
years. Due to the presence of high mountains on both sides of the stretched downriver and the narrowness of the river, the wind current is not significant in the dynamics of this system and tide is the dominant natural forcing. The tide may reach up to Cheng-Ling Bridge in Tahan Stream, the Hsiu-Lang Bridge in Hsintien Stream and the Chiang-Pei Bridge in Keelung River (shown in Figure 1). Except for occasional storm surges induced by hurricanes, the major forcing mechanism of the barotropic flows is the primary tidal constituent $\left(\mathrm{M}_{2}\right.$ tide $)$ at the river mouth. The mean and spring tidal ranges are $2.17 \mathrm{~m}$ and $3.0 \mathrm{~m}$, respectively [32]. The mean tidal range may reach a maximum of $2.39 \mathrm{~m}$ due to convergence of cross section and wave reflection. The Taiwan Water Resources Agency has measured the cross sectional profiles of river at about $0.5 \mathrm{~km}$ intervals since 1969 . These measurements have shown an extensive scouring along the river [32]. The report also 
revealed that the vegetation type in the Kuan-Du wetland, the largest one in the system, has shifted from less salt tolerant types to mangroves. The regional climate is subtropical with the temperature varying between 10 and $35{ }^{\circ} \mathrm{C}$ and annual precipitation ranging between 1500 and $2500 \mathrm{~mm}$; the dry season ranges from November to April and the wet season ranges from May to October.

The morphology of the Danshui River estuary displays different features in each segment, molded by natural forces as well as anthropogenic activities exerted upon the palo-riverbed built ages ago [45]. In the lower reaches immediately downstream of Kuan$\mathrm{Du}$, the riverbed exhibits a deep-cut cross-section, with channel depths of 12-15 m and a sill $(<5 \mathrm{~m})$ in the middle of the riverbed. Further downstream, towards the river mouth, the average depth is $3 \mathrm{~m}$ in the axial region. The river channel broadens with progressively shallower depths; sediment deposits divide the river channel, which is flanked by broad, flat areas of salt marsh and mangrove forest. The lower reaches of the estuary and the adjacent salt marshes are subject to daily tidal inundation.

Liu et al. [27] reported the particle organic matter and biogeochemical processes in Danshui estuary. They found that particle organic carbon concentration decreased gradually with increasing salinity towards the river mouth from the peak values around 266-540 $\mu M$ at the uppermost stations. There were three major types of particulate organic matter in the estuary: natural terrigenous materials consisting mainly of soil and bedrock-derived sediments, anthropogenic wastes and autochthonous materials from the aquatic system. Hsu et al. [22] conducted field measurement in the Danshui River and reported the medium particle sizes (see Table 1). Using the Unified Soil Classification method [9], sand size, silt 
size, and clay size range from $50 \mu m$ to $2000 \mu m, 2 \mu m$ to $50 \mu m$, and less than $2 \mu m$, respectively. Thus, the bed sediments in the estuary mostly belonged to sand size particles. Most clay size and silt size particles were either flushed out to sea or deposited on the shoals. The particle sizes of suspended sediment in the water column range from $10 \mu m$ to $70 \mu m$ that are smaller than that of the bed sediment. This implies that only the smaller particles are eroded from the bed and re-suspended to the water column. Thus, the hydrodynamic and fine cohesive sediment models were implemented in the estuarine system.

\section{MODEL DESCRIPTION}

Mike11 is based on an integrated modular structure with the hydrodynamic module as its core module, and a number of add-on modules, each simulating certain phenomena in river systems [10]. It is an unsteady 1-D model and can simulate both cohesive and non-cohesive sediment transport in addition to water quality. To model cohesive sediment transport, two modules are used: the hydrodynamic (HD) module and the advection/dispersion (AD) module. The HD module contains an implicit, finite difference computation of unsteady flows in rivers and estuaries. It solves the full dynamic and width integrated equations of continuity and conservation of momentum, the Saint-Venant equations [7]:

$$
\begin{aligned}
& \frac{\partial Q}{\partial x}+\frac{\partial A}{\partial t}=q \\
& \frac{\partial Q}{\partial t}+\frac{\partial \alpha \frac{Q^{2}}{A}}{\partial x}+g A \frac{\partial h}{\partial x}+\frac{g n^{2} Q|Q|}{A R^{4 / 3}}=0
\end{aligned}
$$


where $Q\left(\mathrm{~m}^{3} / \mathrm{s}\right)$ is discharge, $h(\mathrm{~m})$ is water level, $A\left(\mathrm{~m}^{2}\right)$ is cross-section area, $q\left(\mathrm{~m}^{2} / \mathrm{s}\right)$ is lateral inflow, $\alpha$ is velocity distribution coefficient, $R(\mathrm{~m})$ is hydraulic radius, $x$ is the horizontal direction, $g\left(\mathrm{~m} / \mathrm{s}^{2}\right)$ is the gravity and $n$ is Manning coefficient. A six-point implicit staggered grid finite difference scheme developed by [1] is used for solving the equations.

The $\mathrm{AD}$ module for transport modeling is based on the one-dimensional equation of conservation of mass of a dissolved or suspended material. The module requires the outputs of the HD module, i.e. discharge and water level, cross-sectional area and hydraulic radius. The basic equation in this module is:

$$
\frac{\partial A C}{\partial t}+\frac{\partial Q C}{\partial x}-\frac{\partial}{\partial x}\left(A K_{H} \frac{\partial C}{\partial x}\right)=-A K_{L} C+C_{2} q+E
$$

where $C$ is concentration, $K_{H}$ is horizontal dispersion coefficient, $K_{L}$ is linear decay coefficient, $C_{2}$ is tributary concentration, $q$ is the tributary inflow per unit length and $E$ is the source/sink term. The above equations are solved numerically using an implicit finite difference scheme, which has a negligible numerical dispersion [10]. The model simulates both temporal and spatial (longitudinal) variations of sediment concentration, as well as accumulated sediment deposits over the simulation period.

The AD module includes a relatively simple description of the erosion and deposition as source/sink terms in the $\mathrm{AD}$ equation. The source / sink terms are:

$$
\begin{array}{ll}
E=\frac{W_{S} C}{h^{*}}\left(1-\frac{v^{2}}{v_{c d}^{2}}\right) & v<v_{c d} \text { (Deposition) } \\
E=\frac{M}{h}\left(1-\frac{v^{2}}{v_{c e}^{2}}\right) & v \geq v_{c e}(\text { Erosion })
\end{array}
$$


where $E$ is net erosion/deposition, $v$ is flow velocity, $v_{c d}$ is critical velocity for deposition, $v_{c e}$ is critical velocity for erosion, $W s$ is fall velocity, $M$ is erodibility coefficient, $h$ is depth and $h^{*}$ is average depth (of the section) through which particles settle. The former version of the model was successfully used by Neary et al. [37] and Parsa et al. [39] for studying the salinity intrusion and sediment transport in tidal rivers, respectively. Parsa et al. [39] showed that MIKE 11 can be used effectively compared to 2-D and even 3-D models.

\section{MODEL CALIBRATION AND VERIFICATION \\ Hydrodynamic (HD) and Advection/Dispersion (AD) module}

For HD module, hourly time series of the water level from 15 March to 30 September, 1994 was used as downstream boundary condition at the river mouth, where the river reaches the sea. For upstream boundary condition, daily fresh water discharge data for the same period were used at the end of the three tributaries. The time step of $\Delta t=100$ seconds and minimum horizontal grid spacing of $\Delta x=1000 \mathrm{~m}$ with the cross sectional profiles at each $500 \mathrm{~m}$, collected by Taiwan Water Conservancy Agency, were specified for the model setup. Wind is an important factor affecting the water level and current at the sea. Due to the presence of high mountains and narrowness in the Danshui River mouth, the wind effects in the estuary were small and can be neglected in the model simulation [29]. In simulating the Danshui River system, the model treated the Danshui River and Tahan Stream as the mainstream and Hsintien Stream and Keelung River as tributaries.

The 1994 water level data was used to calibrate the HD model. The calibrated model has Manning's friction coefficients ranging from 0.032 to 0.026 in Danshui River-Tahan Stream, 0.015 for Hsintien Stream and from 0.023 to 0.016 for Keelung River. Figure 2 
shows the calibration results for Taipei station with a mean absolute error of $14.1 \mathrm{~cm}$ as a sample. To verify the HD model, measured water level and longitudinal mean velocity of 24 June 1994 were used. As an example, figure 3 displays the verification results for PaLing station with a mean absolute error of $6.5 \mathrm{~cm} / \mathrm{s}$ and a maximum error of $20 \mathrm{~cm} / \mathrm{s}$, which is about $35 \%$ of the velocity amplitude.

The salinity data was used to calibrate the mixing process and AD module. The timeseries of salinity from 15 March to 30 September 1994 was used as the downstream boundary condition and the measured constant value of $0.1 \mathrm{ppt}$ was considered as the upstream boundary condition at the end of the tributaries. The simulation started with the initial value of 6 ppt for salinity in all tributaries and the model was executed for two days to warm up.

The field measurements and modeled salinity values of 24 June 1994 were compared in different stations. Figure 4 shows their comparison at Taipei station. The mean absolute error for this station was 0.5 ppt. The calibrated values for dispersion coefficients were 150 $\mathrm{m}^{2} / \mathrm{s}$ for the main River, $5 \mathrm{~m}^{2} / \mathrm{s}$ for Keelung River, and $35 \mathrm{~m}^{2} / \mathrm{s}$ for Hsintien stream. These values are in the acceptable ranges $[15,6]$. To verify the $\mathrm{AD}$ module, the field measurements and computed salinity values of 12 April 1994 were compared in Pa-Ling station and the river mouth. Mean absolute errors of the above comparisons were $0.86 \mathrm{ppt}$ and $0.88 \mathrm{ppt}$, respectively; the maximum error was $5 \mathrm{ppt}$, i.e. about $30 \%$ of the salinity range. Figure 5 shows the verification results in Pa-Ling station.

\section{Cohesive sediment transport (CST) module}


The time series of suspended sediment concentration from 15 March to 30 September, 1994 was used as the upstream and downstream boundary conditions and the initial sediment concentration value of $20 \mathrm{mg} / \mathrm{L}$ was considered for the whole system. The sediment concentrations were measured nearly at mid depth along the river by Taiwan EPA. According to the available Danshui River system data, the free settling velocity of individual particles and critical shear stress of erosion and deposition were determined experimentally [31] and the erosion coefficient was calibrated.

Stokes' law has been used to determine the free settling velocity of the suspended particles less than $62.5 \mu \mathrm{m}$ in diameter in quiescent water $[46,55]$. Liu et al. [31] collected some samples from Danshui River at the top, middle, and bottom layers on the 2nd and the 23rd of February 1999 in three different stations at $1 \mathrm{~km}, 5 \mathrm{~km}$ and $7 \mathrm{~km}$ from the river mouth. The above samplings resulted into a mean diameter of $16.5 \mu \mathrm{m}$ and a standard deviation of $78.8 \mu \mathrm{m}^{2}$ for suspended particles. Therefore, Stokes' law can cautiously be used to determine the free settling velocity of the suspended particles:

$$
W_{s}=\frac{1}{18 v} \frac{\rho_{s}-\rho}{\rho} g D^{2}
$$

where $\rho_{s}\left(\mathrm{gr} / \mathrm{cm}^{3}\right)$ is the density of sediment particles, $\rho\left(\mathrm{gr} / \mathrm{cm}^{3}\right)$ is water density, $v\left(\mathrm{~cm}^{2} / \mathrm{s}\right)$ is the kinematic viscosity of water and $D$ is Stokes' diameter of particles. To consider the size dependence of settling velocity, it can be assumed that $C(D)$ is the concentration of the sediment particles with a Stokes' diameter in the range of $D$ and $D+d D$. Assuming a low concentration without hindered settling and no flocculation, the sediment flux will be:

$$
W_{s} C=\int_{0}^{\infty} W_{s}(D) C(D) d D=K \int_{0}^{\infty} D^{2} C(D) d D
$$


Simplification of this equation leads to [24]:

$$
W_{S}=K\left(D_{m}{ }^{2}+\sigma^{2}\right)
$$

where $D_{m}(\mathrm{~m})$ is the mean diameter and $\sigma^{2}$ is the variance of sediment particles diameter. The variation of $K$ with time is small, therefore $K$ is constant. A settling velocity of 0.00026 $\mathrm{m} / \mathrm{s}$ was used for modeling the settling flux of the total solids.

Critical shear stress for erosion is a function of the dry density of bottom sediments [52]:

$$
\tau_{E}=\alpha\left(\rho_{d}\right)^{\beta}
$$

where $\tau_{E}$ is critical shear stress for erosion, $\rho_{d}\left(\mathrm{gr} / \mathrm{cm}^{3}\right)$ is dry density and $\alpha$ and $\beta$ are constants depending on mud type.

Liu et al. [31] reported the flume experiments that were conducted to yield the critical shear stress and to understand the erosion mechanism of bed sediments collected from the Danshui River estuary. The critical conditions of erosion were quantified using the definition proposed by McNeil et al. [34]. The critical flow velocity, critical shear stress, and dry density were measured for each bed sediment sample. $\tau_{E}$ and $\rho_{d}$ were determined from sediment samples at the Danshui River mouth and Zhu-Wuei station and two equations were obtained: $\tau_{E}=0.83 \rho_{d}{ }^{1.04}\left(R^{2}=0.97\right)$ for Danshui River mouth and $\tau_{E}=0.98 \rho_{d}^{1.41}\left(R^{2}=0.94\right)$ for Zhu-Wuei station [31]. Van Rijn [52] suggested a value between 1.0 and 2.5 for $\beta$ and Mignoit [36] proposed a value of less than 1.0 for $\alpha$. The used constant values are all in line with these ranges.

From the field experiments conducted by Liu et al. [31], $\rho_{d}$ ranges from $0.15 \mathrm{gr} / \mathrm{cm}^{3}$ to $0.2 \mathrm{gr} / \mathrm{cm}^{3}$ in the Danshui estuary and using these values results in $0.07<\tau_{E}<0.15$. Hence, 
a mean value of $0.1 \mathrm{~N} / \mathrm{m}^{2}$ was selected for $\tau_{E}$ in the model simulation. This value is also within the range suggested by Lumborg and Windelin [33] for modeling cohesive sediment transport in tidal areas.

The experiments also showed a value of $0.05 \mathrm{~N} / \mathrm{m}^{2}$ for critical deposition shear stress that is close to the value suggested by Krone [23] and is in the range of 0.03 to $0.08 \mathrm{~N} / \mathrm{m}^{2}$ suggested by Winterwerp et al. [54]. After selection of the above-mentioned parameters, the model was executed with several values of $M$, the erosion coefficient. The best agreement between measured and modeled sediment concentrations was obtained for $M=0.02$ and this constant value was used for the river system.

The field measurements and computed sediment concentrations at Chrong-Yang and Kuan-Du stations in 1994 were used for calibration. Figure 6 shows the comparison between measured and modeled sediment concentrations. The regression coefficient squared, $R^{2}$, of about 0.8 for the respective lines indicates a good agreement.

To verify the cohesive sediment model, the field measurements at Pa-Ling station in 1995 were used. Figure 7 shows the comparison between measured data and modeled results. A good agreement with the regression coefficient of about 0.9 and a mean absolute error of $6.78 \mathrm{mg} / \mathrm{L}$ verified the calibrated erosion coefficient. It should be mentioned that in figures 6 and 7, the modeled high values of sediment concentration were due to floods while nearly all measurements were conducted during non-flood conditions. The absolute mean errors of sediment concentration in these two stations were 6.42 and $4.22 \mathrm{mg} / \mathrm{L}$ respectively.

As another comparison, Figure 8 shows the time history of measured and modeled sediment concentration in Chrong-Yang station in year 1994 with a mean absolute error of 
$4.22 \mathrm{mg} / \mathrm{L}$. It should be mentioned that almost all of the field data were collected under fair weather condition, while the model results showed that the sediment concentration can go up to $180 \mathrm{mg} / \mathrm{L}$ in stormy conditions.

\section{MODEL APPLICATION AND DISCUSSION}

Liu et al. [29] documented that the characteristic two-layered estuarine circulation prevails for most of the time at Kuan-Du station near the river mouth. Though the circulation strengthens with increasing river discharge at low flow, its strength decreases a moderate river discharge and the two-layered circulation ceases at moderately high flow. This has a significant long-term transport implication in the Dasnhui River estuary, which is less of a "material trap" than most large estuaries. The accumulated materials in the estuarine system are flushed frequently. Thus, mean and low freshwater discharges were adopted to investigate the effects of flow and tidal variations on the sediment transport. The used discharges were $Q_{75}$ (the flow which is equaled or exceeded $75 \%$ of time), $Q_{50}$ and $Q_{\text {mean }}$ (see Table 2). The used boundary conditions for sediment concentrations were $40 \mathrm{mg} / \mathrm{L}$ for upstream and $20 \mathrm{mg} / \mathrm{L}$ for the downstream. The salinity was also considered to be $32 \mathrm{ppt}$ at the river mouth and the model was run for 6.5 months from 15 March to 30 September, 1995. The obtained results shown in next figures are tidally averaged.

Figure 9 shows variations of sediment concentrations along the river under various hydrological conditions. The horizontal axis in this figure is the distance from the river mouth. It is seen that when river discharge and bottom stress increase, the sediments can not settle and therefore their concentration in the water column increase. In all flow regimes, the sediment concentration has a local maximum. As discussed by Geyer et al. 
[18] the trapping location depends on the variation of the river flow, while the efficiency of the sediment trapping depends on the characteristics of the convergence zone and the settling velocity of the sediments. This point is where the freshwater meets the sea water (see figure 10). In other words, this point is the limit of salinity intrusion where the salinity becomes $1 \mathrm{ppt}$ [49]. This is not surprising and has been observed in other estuaries as well [e.g. 50,16]. At the limit of salt water intrusion, where the estuarine circulation converges, the river-borne sediments are trapped. In fact, riverine flow meets the seaward flow at the limit of the salinity intrusion and traps near-bottom sediments in the turbidity maximum. This point is also characterized by physical-chemical particle formation due to flocculation of cohesive materials [18, 43]. Hsu et al. [22] used a vertical two-dimensional model and field measurement data of suspended sediment to investigate the turbidity maximum in Danshui River estuary. They found that concentration of suspended sediment at SBF (slack before flood) was higher than that at SBE (slack before ebb). They also concluded that the suspended solids are mainly from the upstream drainage basin rather than the ocean. The vertical two-dimensional model simulation results reveal that at low flow condition, a turbidity maximum occurs at the Kuan-Du station due to the strong estuarine circulation. The model simulation with a much higher river flow condition results in a weaker residual circulation and weaker turbidity maximum. The simulated water surface elevation, current, salinity and cohesive sediment concentration are similar to the model results reported by Liu et al. [31, 32]. However, due to the vertical and lateral averaging in the model, the present model cannot resolve the residual circulation patterns in the estuarine system.

By changing the river discharge, both the limit of salt intrusion and the location of turbidity maximum move downstream. The distances of these points under various 
hydrological conditions are shown in Table 3 . As seen in figure 10, by increasing the river discharge a higher sediment concentration peak is observed. In addition, the increasing trend of sediment concentration starts earlier in low discharges which is due to decrease in water velocity. The decreasing trend (before turbidity maximum) shows that on average, deposition is the dominant process in the river during the spring-neap periods.

Although the turbidity maximum is usually attributed to trapping of particles by the residual flow at the limit of salt intrusion, its characteristics depend on the tidal conditions as well as river discharge [16]. This is shown in figure 11 where (spring and neap tides) tidally averaged sediment concentrations for $Q_{50}$ are plotted along the river. The observed variations in the concentration of suspended sediments are mainly due to the changes in the intensity of resuspension $[5,17]$ and the source of sediments to the water column within this point is usually tidal resuspension of bottom sediments.

In many estuaries, the interaction of tide-induced erosion and deposition may originate a broad zone of abnormally high suspended sediments concentration [16]. Figure 11 also indicates that the location of the turbidity maximum in neap tide is about $1 \mathrm{~km}$ closer to the mouth compared to that of spring tide. This is due to the increased water level at the estuary mouth caused by increased tidal range in spring tides. Spring tides also enhance the deposition of the sediments in the intertidal areas of estuary head due to long slack water period over high water [11], a feature observed in Danshui River. Considering the abovementioned points, it could be concluded that the sediment transport in this system is mainly governed by freshwater discharge and partially by tidal variations. In addition, both the limit of salt intrusion and the maximum sediment concentration depend on the river discharge at flood events. These findings are supported by results obtained from more 
sophisticated 2-Dimensional and 3-Dimensional models [e.g. 24, 31]. We believe that wind set-up and/or storm surges also contribute to change the water level and to affect the sediment transport in estuary, but these features have not been measured yet. These kinds of measurements are planned for the future.

To investigate the effects of discharge variations on the longitudinal distribution of sediment concentration, two stations were selected. Figures 12 and 13 show the temporal variations of sediment concentrations at Kuan-Du and Chrong-Yang stations, respectively. The Kuan-Du station is located about $7 \mathrm{~km}$ from the mouth and is under the influence of salinity intrusion (the minimum salt intrusion length is $15 \mathrm{~km}$ ). As seen, the sediment concentration in this station is not a function of river discharge and has a mean value of 13 $\mathrm{mg} / \mathrm{L}$. On the other hand, the sediment concentration at Chrong-Yang station (which is located $20 \mathrm{~km}$ from the mouth) depends mostly on the river discharge. The mean concentration is $5.69 \mathrm{mg} / \mathrm{L}$ (for $Q_{75}$ ), $7.15 \mathrm{mg} / \mathrm{L}$ (for $Q_{50}$ ) and $13.14 \mathrm{mg} / \mathrm{L}$ (for $Q_{\text {mean }}$ ). This means that the sediment concentration at this station mainly depends on the freshwater discharge and is independent of tidal variation.

An important point in Tahan Stream is located close to the junction of Hsintien Stream and main branch (figure 1). At this point, a diversion channel is constructed and during low discharges, it experiences bed profile changes and degradation of diversion channel performance. The model (figure 14) also shows that by increasing the water discharge from $Q_{75}$ to $Q_{\text {mean }}$, the mean concentration increases from $6.13 \mathrm{mg} / \mathrm{L}$ to $22.78 \mathrm{mg} / \mathrm{L}$. It reveals that increase of freshwater discharge results in increase of the sediment concentration because more resuspended sediment would be disturbed from the bed. The issues associated with increasing sediment concentration include impairment of fish habitat and 
river attraction as well as degradation of water supply efficiency. Therefore, sediment traps are required in the upstream reaches for reducing the effects on environmental contamination.

\section{SUMMARY AND CONLUSION}

The hydrodynamics, salinity distribution and cohesive sediment processes of Danshui River estuarine system have been studied numerically, using a 1-D model. First, the HD model was calibrated and verified by comparing water level and longitudinal mean velocity time series data of 1994. Then, the longitudinal dispersion coefficient was estimated using the salinity time series of 1994 to calibrate and verify the AD model. Finally, the erosion coefficient was estimated using suspended sediment concentration time series of 1994 and 1995. The good agreement between field measurements and computed values and the acceptable mean absolute errors showed that a 1-D model can successfully simulate the cohesive sediment behavior in this estuary. The model can be used for stormy conditions even though it could not be verified completely due to the lack of data.

The model was then used to study the effects of flow and tidal variations on the sediment transport. It was found that the sediment concentration has a local maximum at the limit of salinity intrusion, the point where the freshwater meets the seawater. The results indicated that for $Q_{50}$, the turbidity maximum location in neap tide is about $1 \mathrm{~km}$ closer to the mouth compared to that of spring tide. In addition, it was noted that both the limit of salt intrusion and the location of maximum sediment concentration depend on the river discharge at flood events. It was found that deposition is the dominant sediment process in the river during spring-neap periods. It was also found that the sediment concentration in 
Kuan-Du station (located at $\mathrm{Km} \mathrm{7}$ ) is not a function of river discharge while the sediment concentration at Chrong-Yang station (located at $\mathrm{Km}$ 20) depends on the river discharge.

\section{ACKNOWLEDGMENT}

The measured data were mostly provided by the Taiwan Water Resources Agency. The authors also express their special appreciation to Abbas Dorostkar and Hengameh Moshfeghi, whose comments and assistance led to substantial improvement of this paper. We also thank Neil b. Fazel for editing the manuscript. This work was partly supported by the Deputy of Research, Iran University of Science and Technology and the first author was a recipient of a Gledden Senior Visitor Fellowship from UWA, Australia. 


\section{REFERENCES}

1. Abbott, M.B. \& Ionescu, F. (1967). On the numerical computation of nearly-horizontal flows, Journal of Hydraulic Research, 5, 97-117.

2. Ali, A., Mynett, A.E. \& Azam, M. H. (2007). Sediment dynamics in the Meghna estuary, Bangladesh: A model study, Journal of Waterway, Port, Coastal and Ocean Engineering, ASCE, 133(4), 255-263.

3. Burchard, H. \& Baumert, H. (1998). The formation of estuarine turbidity maximum due to density effects in the salt wedge: A hydrodynamic process study, Journal of Physical Oceanography, 28, 309-321.

4. Cancino, L. \& Neves, R. (1999). Hydrodynamic and sediment suspension modelling in estuarine systems, Part II: Application to the Western Scheldt and Gironde estuaries, Journal of Marine Systems, 22, 117-131.

5. Castaing, P. \& Allen, G.P. (1981). Mechanisms controlling seaward escape of suspended sediment from the Gironde: a macrotidal estuary in France. Marine Geology, 40, $101-118$.

6. Chapra S. C. (1997). Surface Water-Quality Modeling, (McGraw-Hill, New York, 844 pp.)

7. Chow, V. T. (1983). Open Channel Hydraulics, (McGraw Hill, 680 pp.)

8. Cole, P. \& Miles, G. V. (1983). Two-dimensional model of mud transport. Journal of Hydraulic Engineering, ASCE, 109, 1-12.

9. Das, B. M. (1990). Principal of geotechnical engineering (second edition). PWS-KENT, Boston, Massachusetts. 
10. DHI Software Group (2006). Mike11 Reference Manual, Danish Hydraulic Institute, Denmark

11. Dyer, K. R. (1997). Estuaries: A Physical Introduction, John Wiley and Sons, 195 pp.

12. Eisma, D. (1990). Transport and deposition of suspended matters in the North Sea and the relation with the coastal situation, pollution and bottom fauna distribution, Aquatic Science, 3, 181-216.

13. Falconer, R. A. \& Chen, Y. (1996). Modelling sediment transport and water quality processes on tidal floodplains. (In M. G. Anderson, D. E. Walling and P. D. Bates (Eds.), Flood Plain Processes, ( pp. 361-398) Wiley, New York)

14. Fettweis, M., Francken, F., Pison, V. \& Van den Eynde, D. (2006). Suspended particle matter dynamics and aggregate sizes in a high turbidity area, Marine Geology, 235, 63-74.

15. Fischer, H. B., List, E. J., Koh, R. Y. C., Imberger, J. \& Brooks, N. H. (1979)Mixing in Inland and Coastal Waters, (Academic Press, San Diego, Calif)

16. Fortes Lopes, J., Dias, J. M. \& Dekeyser, I. (2006). Numerical modeling of cohesive sediment transport in the Ria de Aveiro lagoon, Portugal, Journal of Hydrology, 319, 176198.

17. Geyer, W.R., Woodruff, J.D. \& Traykovski, P. (2001). Sediment trapping and transport in the Hudson River. Estuaries, 24, 670-679.

18. Geyer, W.R., Hill, P.S. \& Kineke, G.C. (2004). The transport, transformation and dispersal of sediment by buoyant coastal flows. Continental Shelf Research, 24, 927-949.

19. Gleizon, P., Punt, A.G. \& Lyonsb, M.G. (2003). Modelling hydrodynamics and sediment flux within a macrotidal estuary: problems and solutions The Science of Total Environment, 314, 589-597. 
20. Hayter, E. J. \& Mehta, A. J. (1986). Modelling cohesive sediment transport in estuarine waters. Applied Mathematical Modelling, 10, 294-303.

21. Ho, C. S. (1975). An introduction to the geology of Taipei, Taiwan, Republic of China. The Ministry of Economic Affairs, 153pp.

22. Hsu, M. H., Wu, C. R. , Liu W. C. \& Kuo, A. Y. (2006). Investigation of turbidity maximum in a mesotidal estuary, Taiwan, Journal of American Water Resources Association, 42(4), 901-914.

23. Krone, R.B. (1962). Flume Studies of the Transport of Sediment in Estuarine Shoaling Processes. Final Report to San Francisco District US Army Corps of Engineers, Washington DC. University of California, Berkeley.

24. Le Normant, C. (2000). Three dimensional modelling of sediment transport in the Loire estuary, Hydrological Processes, 14, 2231-2243.

25. Lin, J. \& Kuo, A. (2003). A model study of turbidity maxima in the York River estuary, Virginia, Estuaries, 26(5), 1269-1280.

26. Lin, P., Huan, J. \&, Li, X. (1983). Unsteady transport of Suspended load at small Concentrations. Journal of Hydraulic Engineering, ASCE, 109, 86-98.

27. Liu, K. K., Kao, S. J., Wen, L. S. \& Chen, K. L. (2007). Carbon and nitrogen isotopic compositions of particle organic matter and biochemical processes in the eutrophic Danshuei Estuary in northern Taiwan. Science of the Total Environment, 382, 103-120.

28. Liu, W. C. (2006). Modelling circulation and vertical mixing in estuaries. Proceedings of the Institute of Civil Engineering, Maritime, 159(2), 67-76. 
29. Liu W.C., Hsu, M. H. \& Kuo, A. Y. (2001a). Investigation of long-term transport in the Tanshui River estuary, Taiwan. Journal of Waterway, Port, Coastal, and Ocean Engineering, ASCE, 127(2), 61-71.

30. Liu, W. C., Hsu, M. H., Kuo, A. Y. \& Kuo, J. T. (2001b). The influence of river discharge on salinity intrusion in the Tanshui estuary, Taiwan. Journal of Coastal Research, 17(3), 544-552.

31. Liu, W. C., Hsu, M. H \& Kuo, A. Y. (2002). Modelling of Hydrodynamics and Cohesive Sediment Transport in Tanshui River Estuarine System, Taiwan, Marine Pollution Bulletin, 44, 1076-1088.

32. Liu, W. C., Hsu M. H., Wu, C.R., Wang, C.F. \& Kuo, A. Y. (2004). Modeling salt intrusion in Tanshui River Estuarine system-case study contrasting now and then, Journal of Hydraulic Engineering, 130, 849-859.

33. Lumborg, U. \& Windelin, A. (2003). Hydrography and cohesive sediment modeling: application to the Romo Dyb tidal area, Journal of Marine Systems, 38, 287-303.

34. McNeil, J., Taylor, C. \& Lick, W. (1996). Measurements of erosion of undisturbed bottom sediments with depth. Journal of Hydraulic Engineering, 122, 316-324.

35. Mehta, A.J., Hayter, E.J., Parker, W.R., Krone, R.B. \& Teeter, A.M. (1989). Cohesive sediment transport: Part I. Process description. Journal of Hydraulic Engineering, 115, 1076-1093.

36. Mignoit, C. (1968). Etude des proprietes physique de differents sediments tres fins et de leur comportment sous des actions hydrodynamiques. La Houille Blache, 23, 591-620. 
37. Neary, V.S., Wright, S.A. \& Bereciartua, P. (2001). Case study: Sediment transport in proposed geomorphic channel for Napa River, Journal of Hydraulic Engineering, ASCE, $127,901-910$.

38. Parker, W.R. (1997). On the characterization of cohesive sediment for transport modelling. (In N. Burt, R. Parker and J. Watts (Eds.), Cohesive Sediments, Chap. 1. Wiley, Chichester, $3-15)$

39. Parsa, J., Etemad-Shahidi, A. Hosseiny, S. \& Yeganeh-Bakhtiary, A. (2007) Evaluation of computer and empirical models for prediction of salinity intrusion in the Bahmanshir Estuary, Journal of Coastal Research, SI 50, 658-662.

40. Rae, J.E. (1997). Trace metals in deposited intertidal sediments. (In T.D. Jickells and J.E. Rae, (Eds.), Biogeochemistry of Inter- tidal Sediments, vol. 9. Cambridge Univ. Press, Cambridge, 16-41)

41. Rao, A., Dash, S. \& Babu, S. V. (2004). Numerical study of the circulation and sediment transport in the Mahanadi Estuary, Natural Hazards, 32, 219-237.

42. Scarlatos, P. D. (1981). On the numerical modelling of cohesive sediment transport. Journal of Hydraulic Research, 19, 61-68

43. Schubel, J.R. (1972). Distribution and transportation of suspended sediment in Upper Chesapeake Bay. Geological Society of America, 133, 151-167.

44. Soil-Survey-Staff. (1999). Soil taxonomy: a basic system of soil classification for making and interpreting soil surveys. Agricultural handbook, vol. 436, Washington: USDA-NRCS, pp. 120.

45. Song, G. S., Wen, L. S., Liu, K. K. \& Liu, P. K. (2002). Underwater topography in the downstream portion of Tanshui Rvier. Acta Ocean Taiwanica, 40, 25-30. 
46. Sverdrup, H.V., Johnson, M.W. \& Fleming, R.H. (1942). The Oceans. (Prentice-Hall, New York)

47. Teisson, C. (1991). Cohesive suspended sediment transport: feasibility and limitations of numerical modelling, Journal of Hydraulic Research, 29, 755-769.

48. Tett, P.B., Joint, I.R., Purdie, M., Barres Oosterhuis, S., Daberi, F., Hannah, D.K., Millls, D., Plummers, A.J., Pomroy, Walne, A.W. \&, Witte, A.J. (1993). Bilological consequences of tidal stirring gradients in the North Ocean, Phylosophical Transaction Royal Society of London, A 343, .493-508.

49. Tuin, H.V., Le Huu Mikhailov, V. , Roelfzema, A. \& Volker, A. (1991). Guidelines on The Study of Sea Water Intrusion into Rivers, (UNESCO, France, 202 pp.)

50. Uncles, R. J. \& Stephens, J. A. (1989). Distribution of suspended sediment at high water in a microtidal estuary, Journal of Geophysical Research, 94, 14395-14405.

51. Van Der Lee, W.T.B. (2000). The settling of mud flocs in the Dollard estuary, The Netherlands. Netherlands Geographic Studies, 274, 15- 121.

52. Van Rijn L. C. (1993). Principle of Sediment Transport in Rivers, Estuaries and Coastal Seas, (Netherlands, Aqua Publications, 1386 pp.)

53. Van Wijngaarden, M. (1999). A two-dimensional model for suspended sediment transport in the southern branch of the Rhine-Meuse estuary, the Netherlands. Earth Surface Process Land, 24, 1173-1188.

54. Winterwerp, J.C., Cornelisse, J.M. \& Kuijper, C. (1991). A laboratory study on the behavior of mud from the Western Scheldt under tidal conditions In: Nearshore and Estuarine Cohesive Sediment Transport workshop, St. Petersburg, Florida, 295-313. 
55. Yang C. T. (1996). Sediment Transport, Theory and Practice, (McGraw-Hill, New York)

56. Zheng, L., Chen, C.S., Alber, M. \& Liu, H. (2003). A modeling study of the Satilla River estuary, Georgia, II: Suspended sediment, Estuaries, 26(3), 670-679. 


\section{Figure caption}

Figure 1. The map of the Danshui River estuarine system (values in the parentheses represent the distance from the Danshui River mouth).

Figure 2. Hydrodynamic module calibration, water level time series (a) Taipei station,

1994 (b) Hsin-Hai station in1994.

Figure 3. Hydrodynamic module verification: (a) comparison of longitudinal velocity time series at Pa-Ling station on June, 24, 1994 (b) comparison of longitudinal velocity time series at Taipe station on June, 24, 1994.

Figure 4. Avection/Dispersion module calibration: comparison of salinity time series at Taipei station on 24 June 1994.

Figure 5. Advection/Dispersion module verification: (a) comparison of salinity time series at Pa-Ling station on 12 April 1994, (b) comparison of salinity time series at Kuan-Du station on 24 June 1994.

Figure 6. Calibration of cohesive sediment transport module: comparison of measured and modeled suspended sediment concentrations at Chrong-Yang station, 1994 showing that high values were not captured in the measurements.

Figure 7. Verification of cohesive sediment transport module: comparison of measured and modeled suspended sediment concentrations at Kuan-Du station, 1994 showing that high values were not captured in the measurements.

Figure 8. Verification of cohesive sediment transport module: comparison of measured and modeled suspended sediment concentrations at Pa-Ling station, 1995.

Figure 9. Comparison of sediment concentrations along the river under various hydrological conditions. 
Figure 10. Comparison of salinity variations along the river under various hydrological conditions.

Figure 11. Comparison of sediment concentrations along the river in spring and neap tide periods.

Figure 12. Temporal variations of suspended sediment concentration at Kuan-Du station under various hydrological conditions. Time starts from 00.00 15 March 1994.

Figure 13. Temporal variations of suspended sediment concentration at Chrong-Yang station under various hydrological conditions. Time starts from 00.00 15 March 1994.

Figure 14. Temporal variations of sediment concentration at Km 19.735 of Tahan Stream under various hydrological conditions. 
Table 1. Medium particle sizes at different stations.

\begin{tabular}{|c|c|c|c|c|c|c|c|c|}
\hline \multirow{3}{*}{ Station } & \multirow{3}{*}{$\begin{array}{l}\text { Dan- } \\
\text { Hai }\end{array}$} & \multicolumn{5}{|c|}{ Chrong- } & \multirow[t]{2}{*}{ Chung- } & \multirow[t]{2}{*}{ Chung } \\
\hline & & Zhu- & Kuna- & Yang & Taipei & Highway & & \\
\hline & & Wei & $\mathrm{Du}$ & Bridge & Bridge & Bridge & & Bridge \\
\hline Size & & & & & & & & \\
\hline$(\mu m)$ & 300 & 400 & 200 & 450 & 300 & 120 & 200 & 200 \\
\hline
\end{tabular}

Table 2. Freshwater discharges $\left(\mathrm{m}^{3} / \mathrm{s}\right)$ under various hydrological conditions.

\begin{tabular}{cccc}
\hline Hydrological condition & Keelung & Tahan & Hsintien \\
\hline$Q_{\text {mean }}$ & 26.1 & 62.1 & 72.7 \\
$Q_{50}$ & 9.82 & 29.65 & 44.43 \\
$Q_{75}$ & 3.5 & 18.1 & 20.43 \\
\hline
\end{tabular}

Table 3. Locations of maximum sediment concentrations under various hydrological conditions.

\begin{tabular}{cc}
\hline Hydrologic & Distance from the river \\
condition & mouth $(\mathrm{km})$ \\
\hline$Q_{75}$ & 26 \\
$Q_{50}$ & 22.5 \\
$Q_{\text {mean }}$ & 15 \\
\hline
\end{tabular}




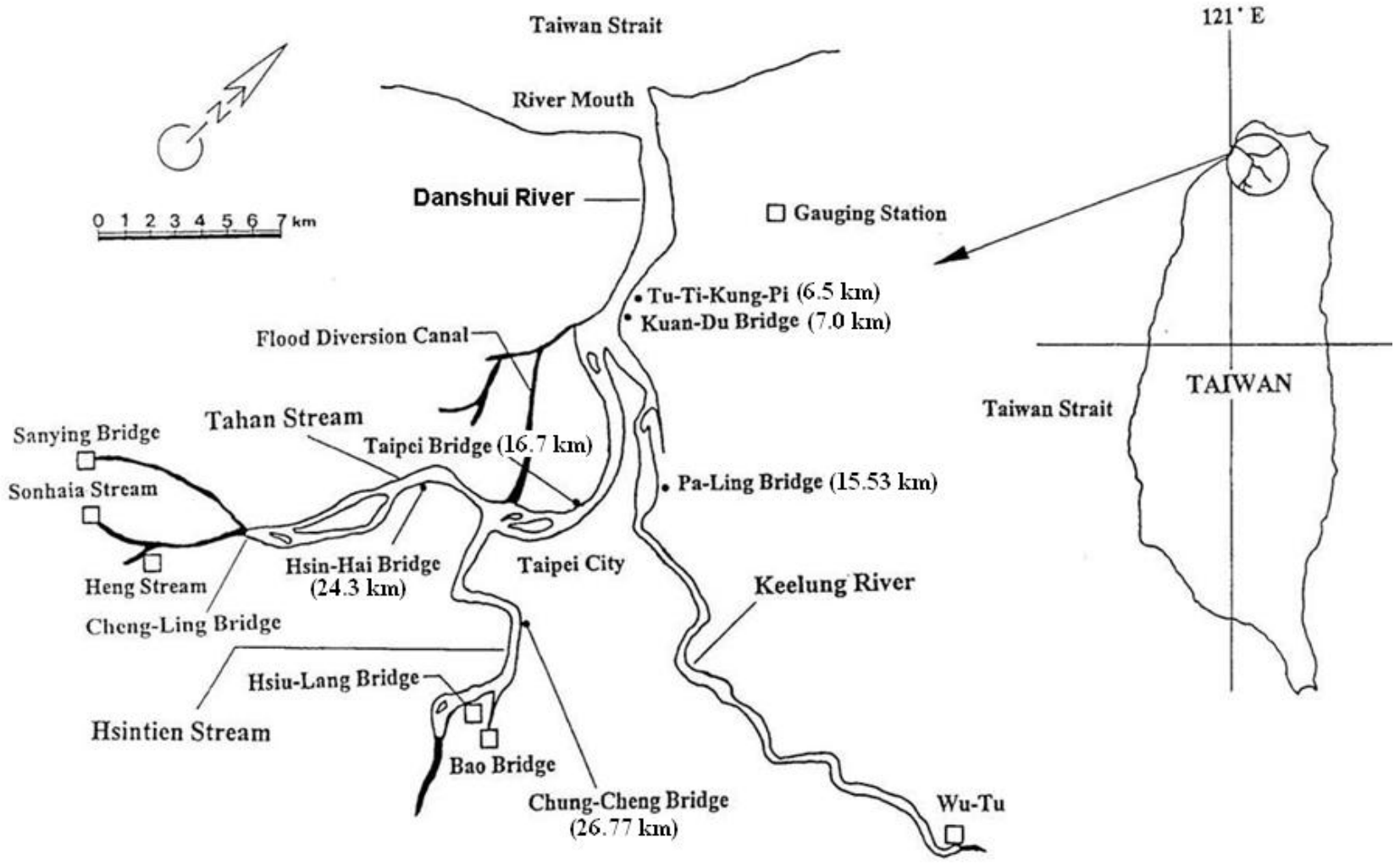

Figure 1. The map of the Danshui River estuarine system (values in the parentheses represent the distances from the Danshui River mouth). 
(a)

Taipei

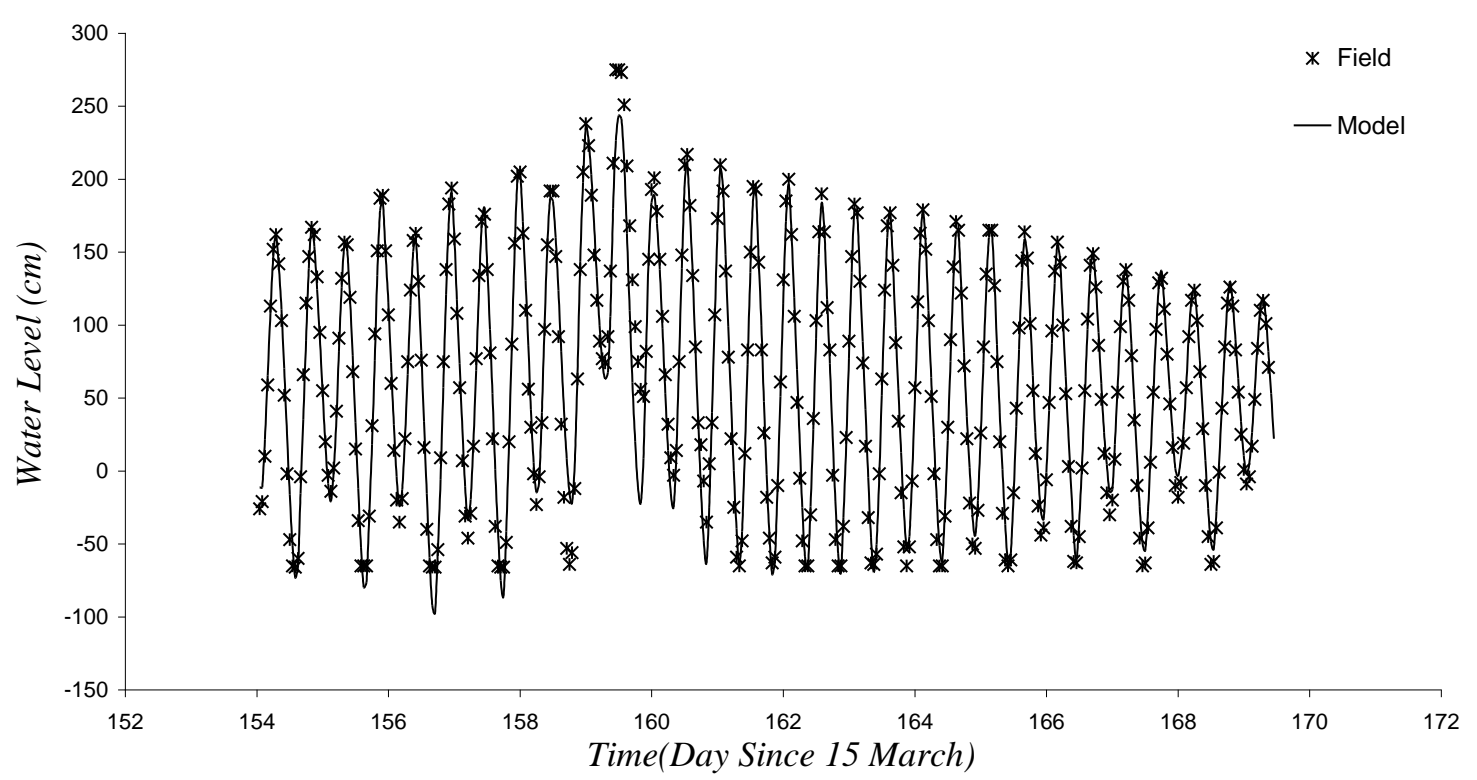

(b)

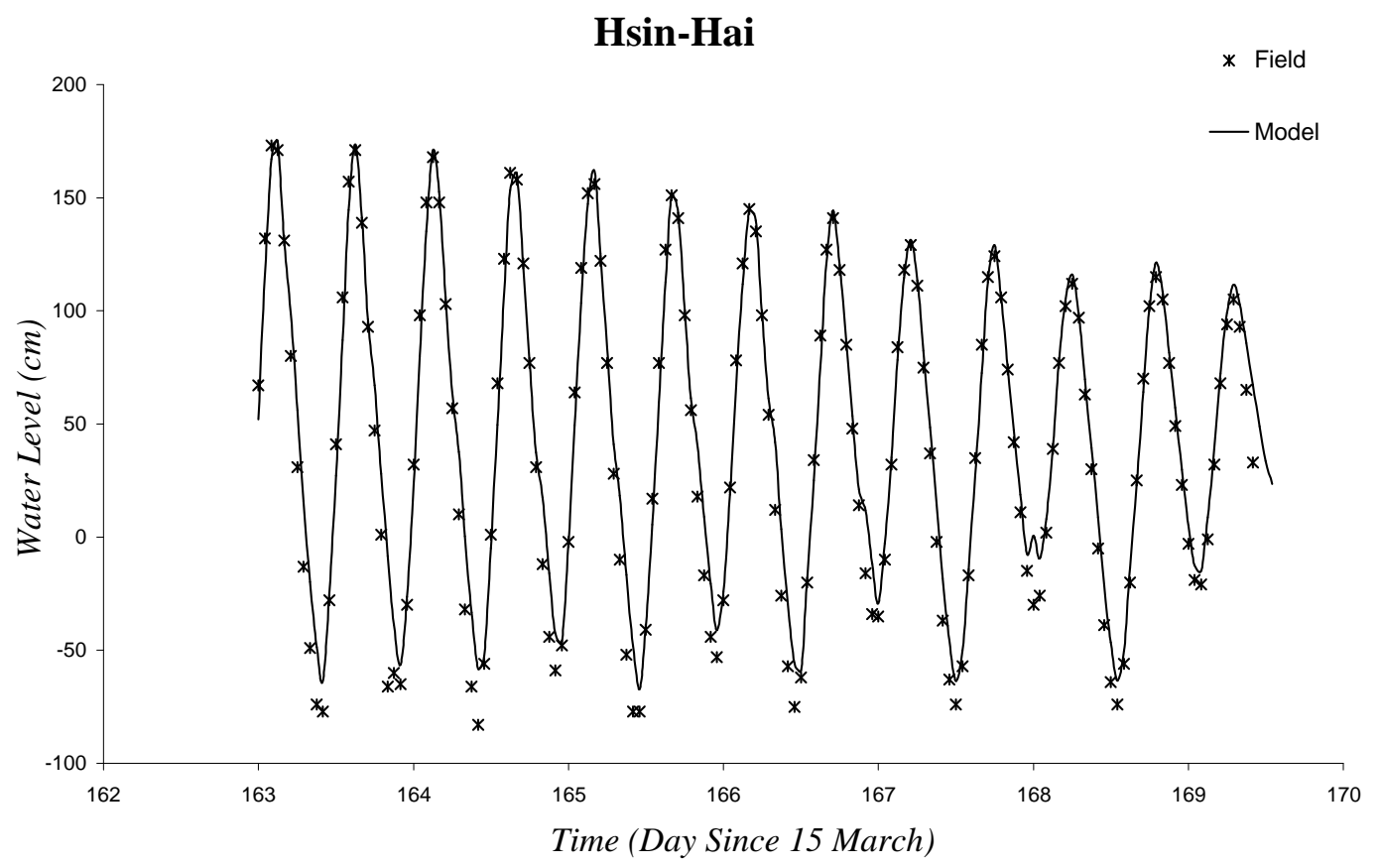

Figure 2. Hydrodynamic module calibration, water level time series (a) Taipei station, 1994 (b) Hsin-Hai station in1994. 
(a)

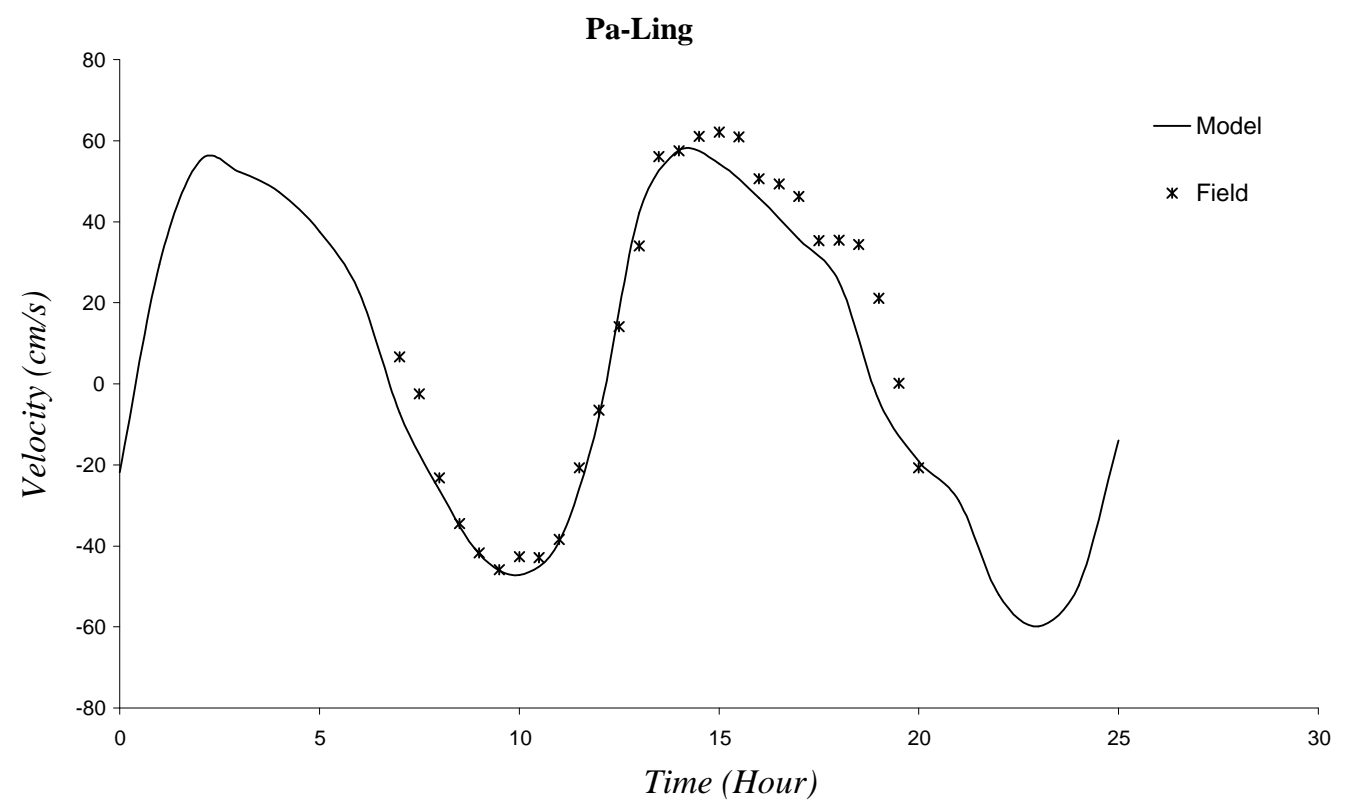

(b)

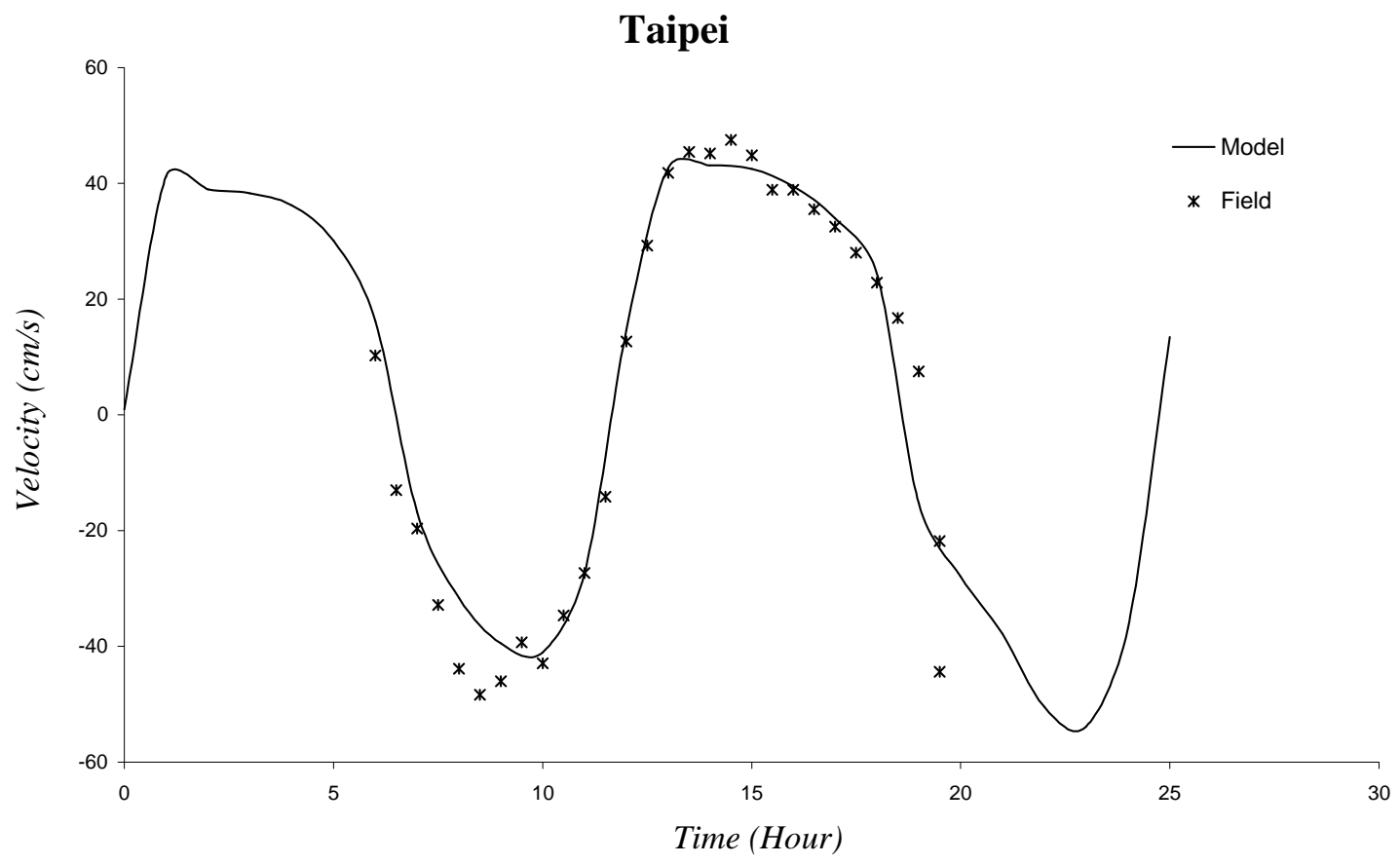

Figure 3. Hydrodynamic module verification: (a) comparison of longitudinal velocity time series at Pa-Ling station on June, 24, 1994 (b) comparison of longitudinal velocity time series at Taipe station on June, 24, 1994. 


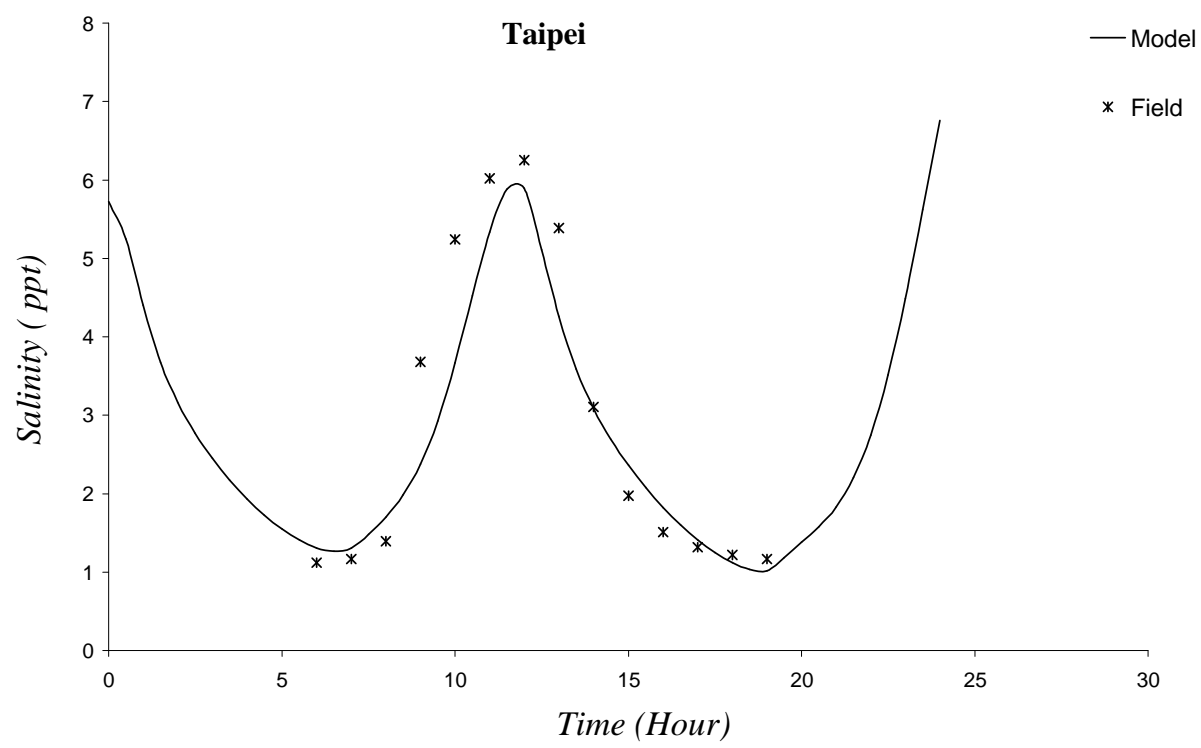

Figure 4. Avection/Dispersion module calibration: comparison of salinity time series at Taipei station on 24 June 1994. 
(a)

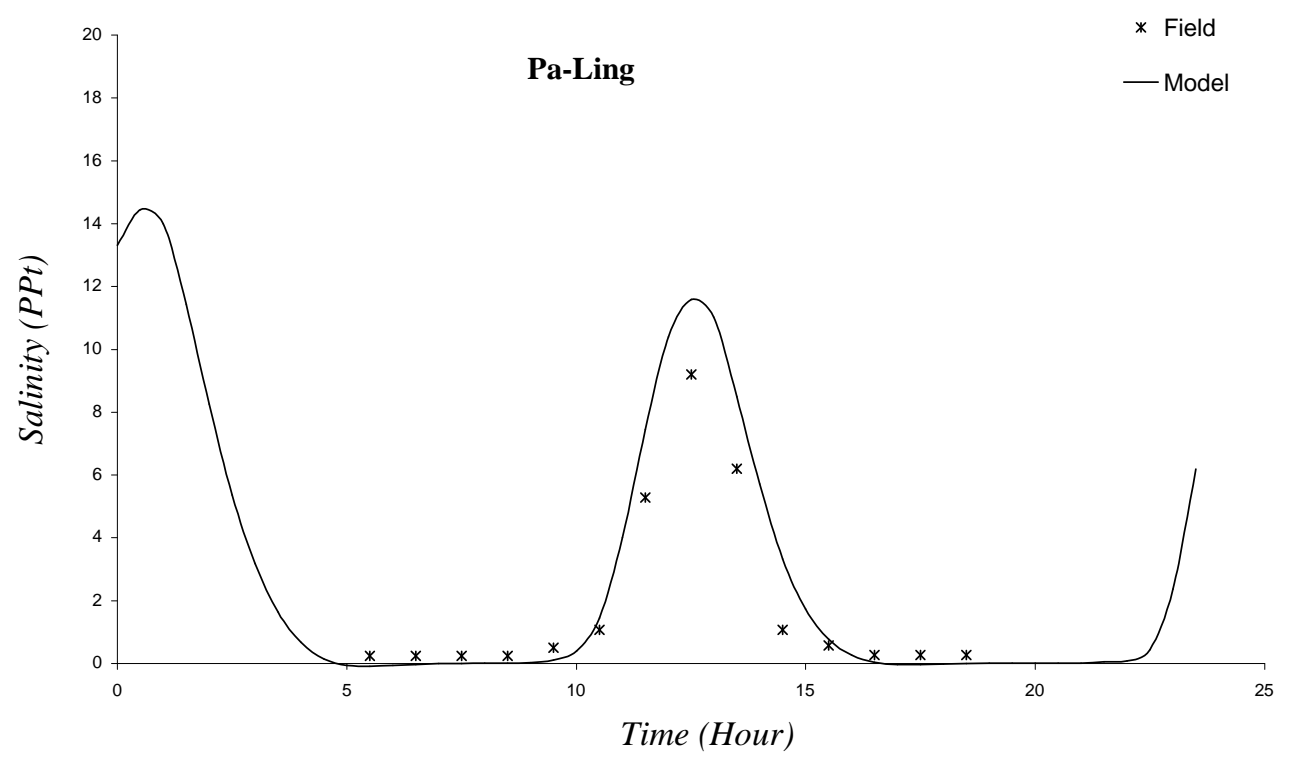

(b)

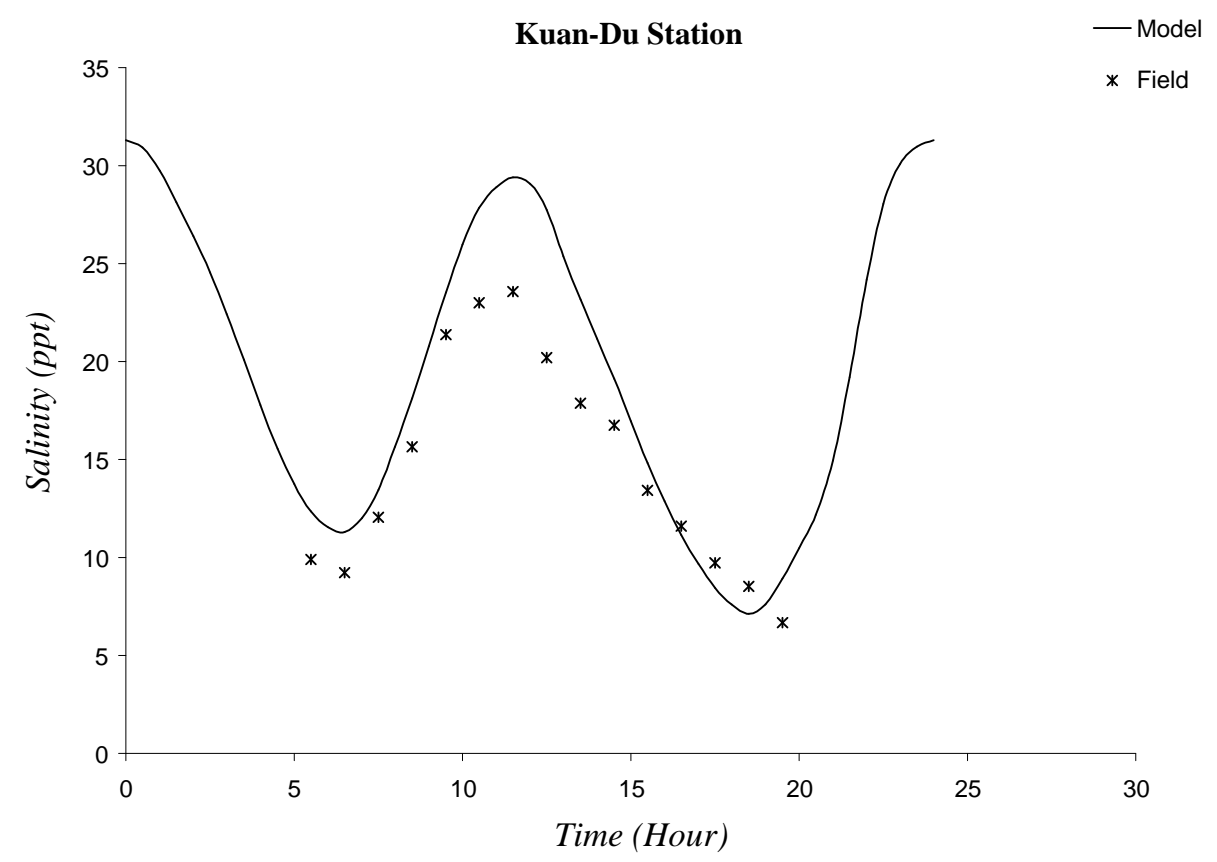

Figure 5. Advection/Dispersion module verification: (a) comparison of salinity time series at Pa-Ling station on 12 April 1994, (b) comparison of salinity time series at Kuan-Du station on 24 June 1994. 


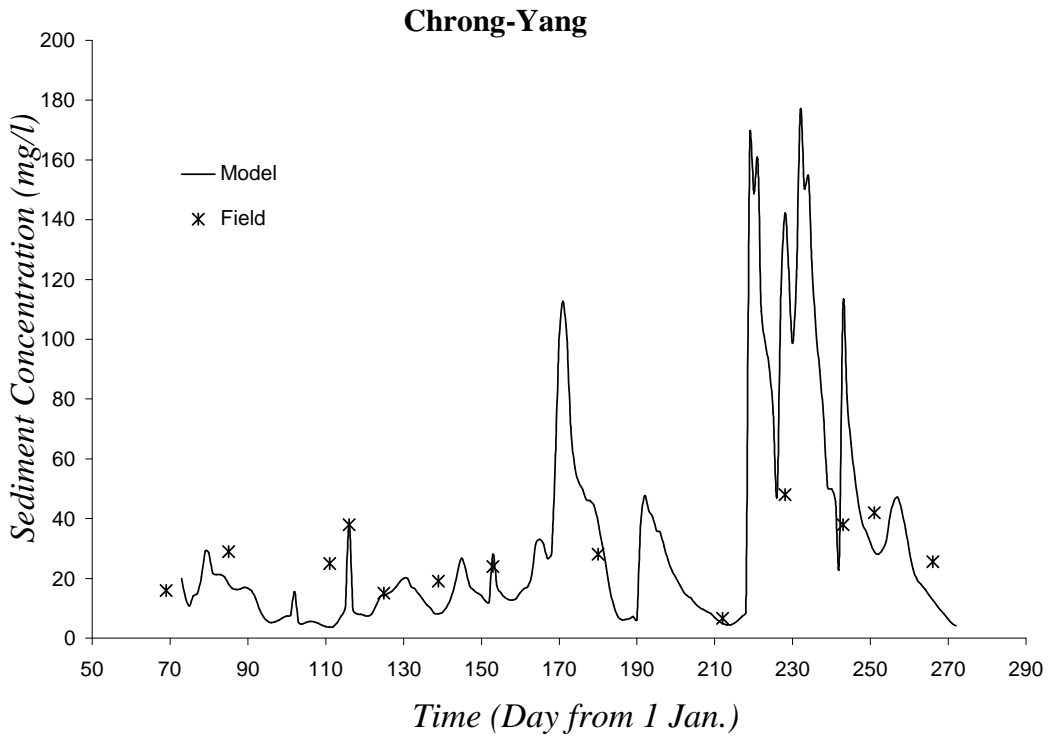

Figure 6. Calibration of cohesive sediment transport module: comparison of measured and modeled suspended sediment concentrations at Chrong-Yang station, 1994 showing that high values were not captured in the measurements. 


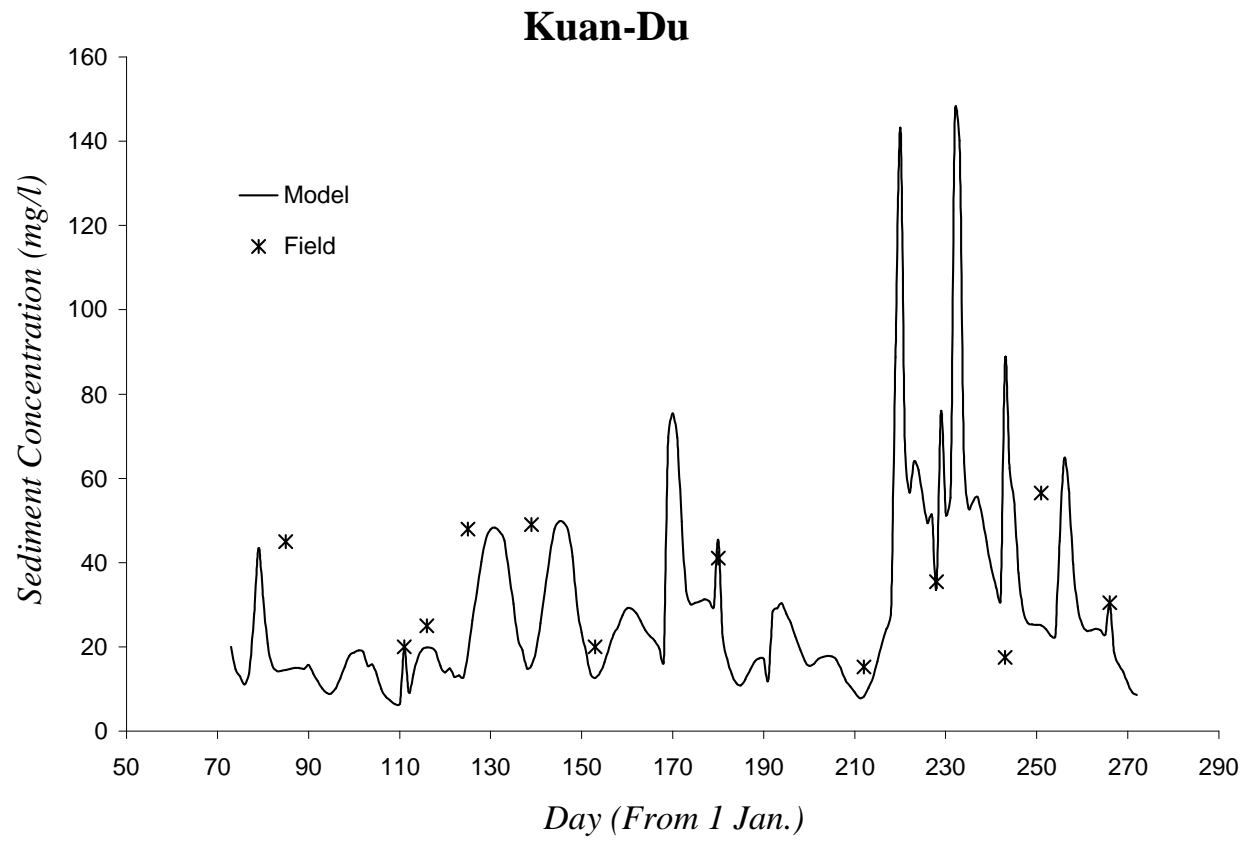

Figure 7. Verification of cohesive sediment transport module: comparison of measured and modeled suspended sediment concentrations at Kuan-Du station, 1994 showing that high values were not captured in the measurements. 


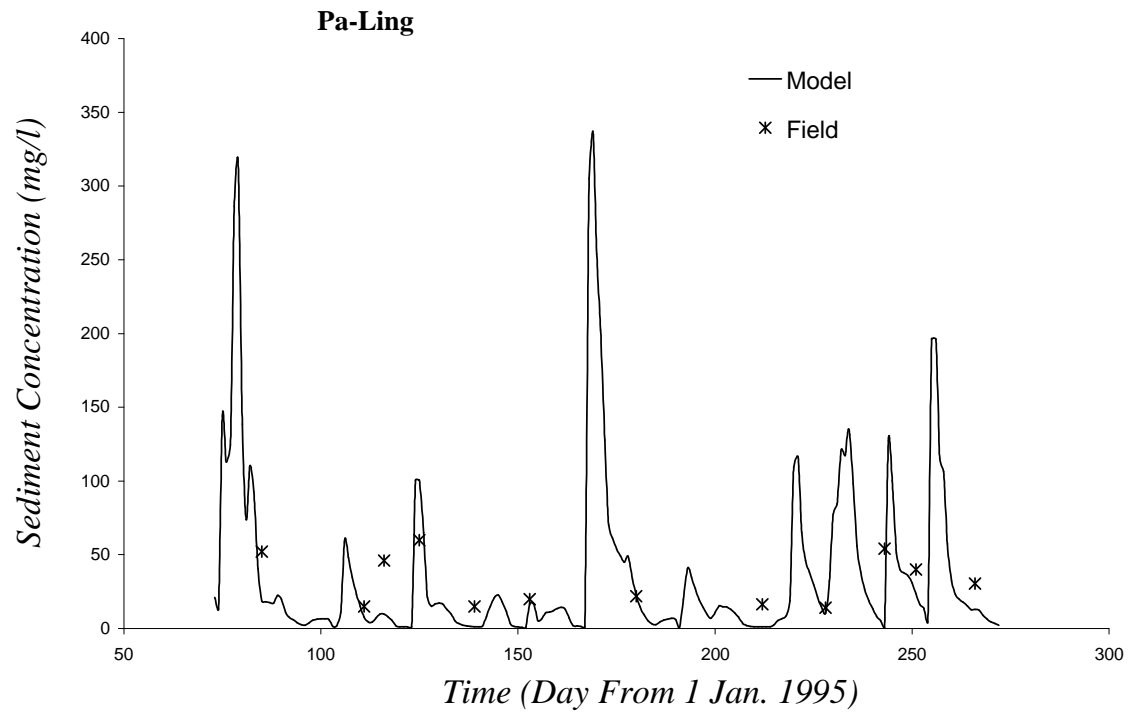

Figure 8. Verification of cohesive sediment transport module: comparison of measured and modeled suspended sediment concentrations at Pa-Ling station, 1995. 


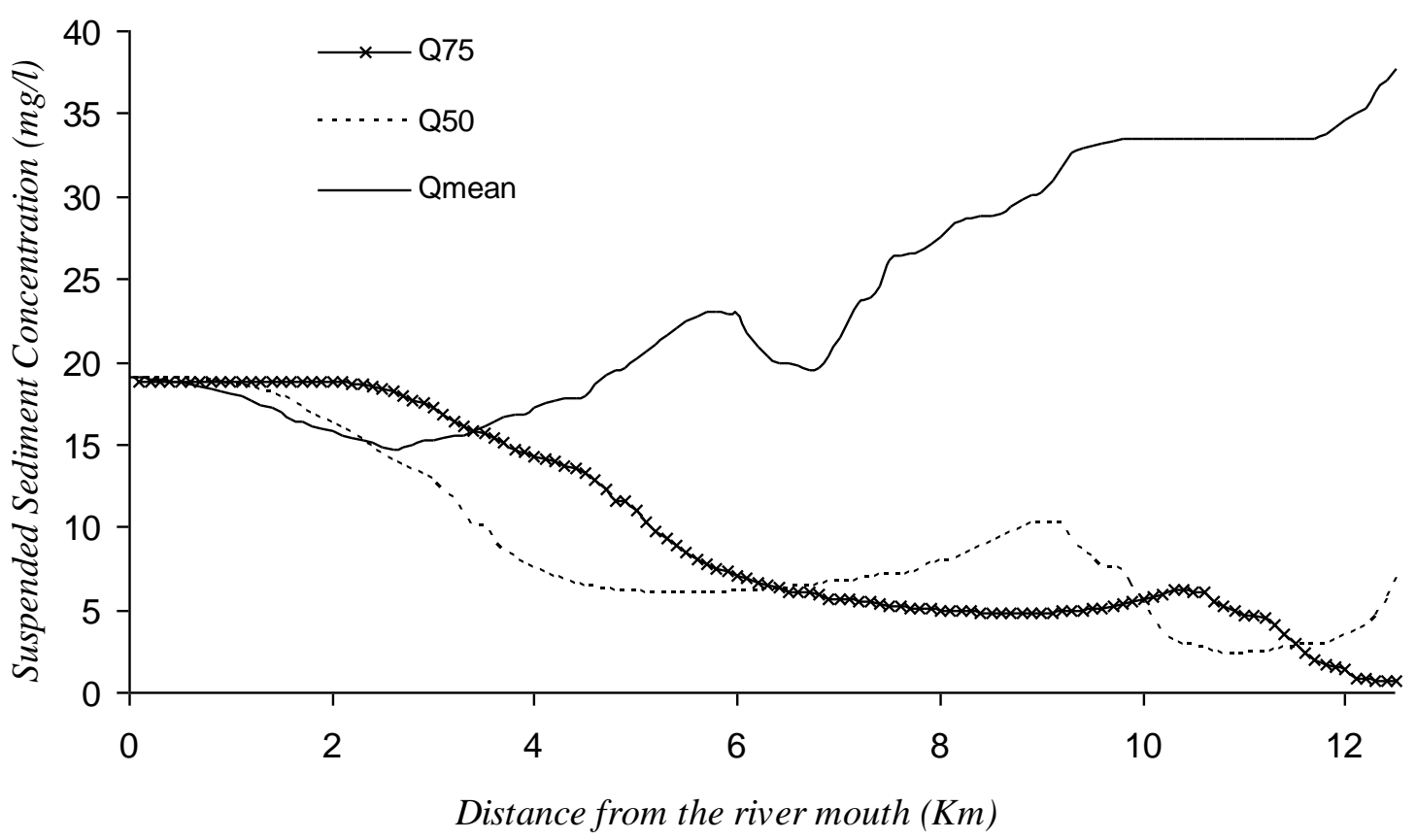

Figure 9. Comparison of sediment concentrations along the river under various hydrological conditions. 


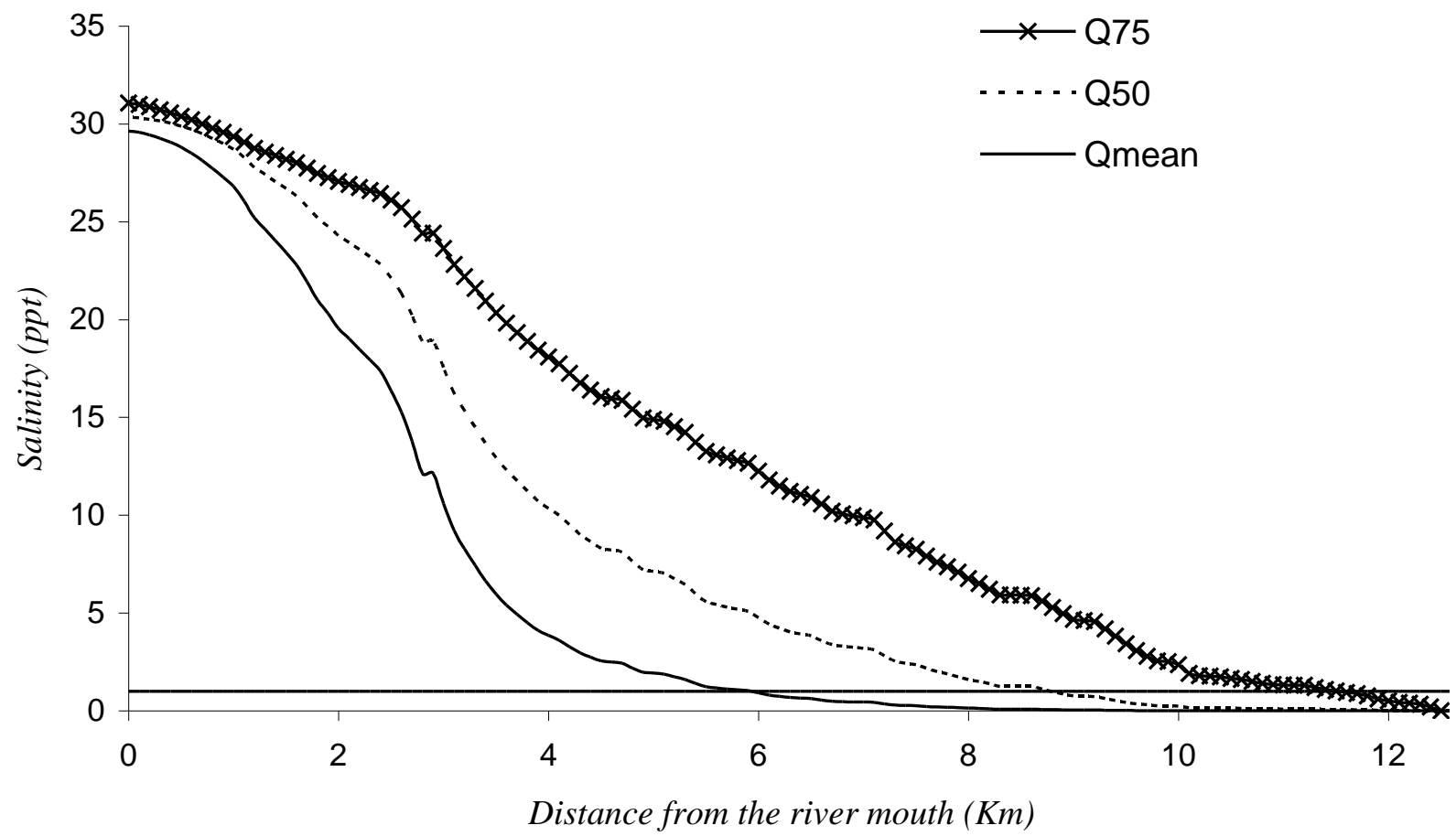

Figure 10. Comparison of salinity variations along the river under various hydrological conditions. 


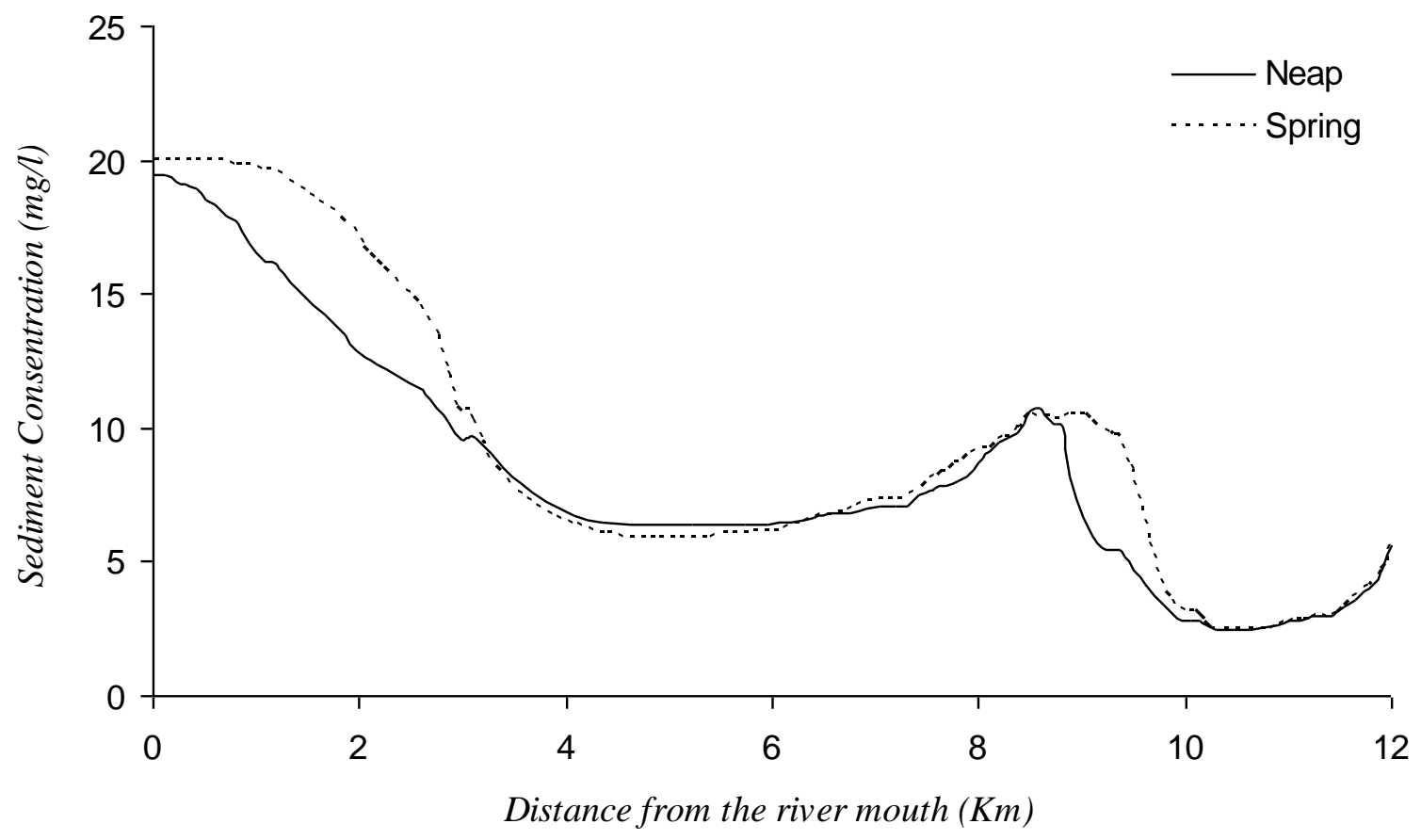

Figure 11. Comparison of sediment concentrations along the river in spring and neap tide periods. 


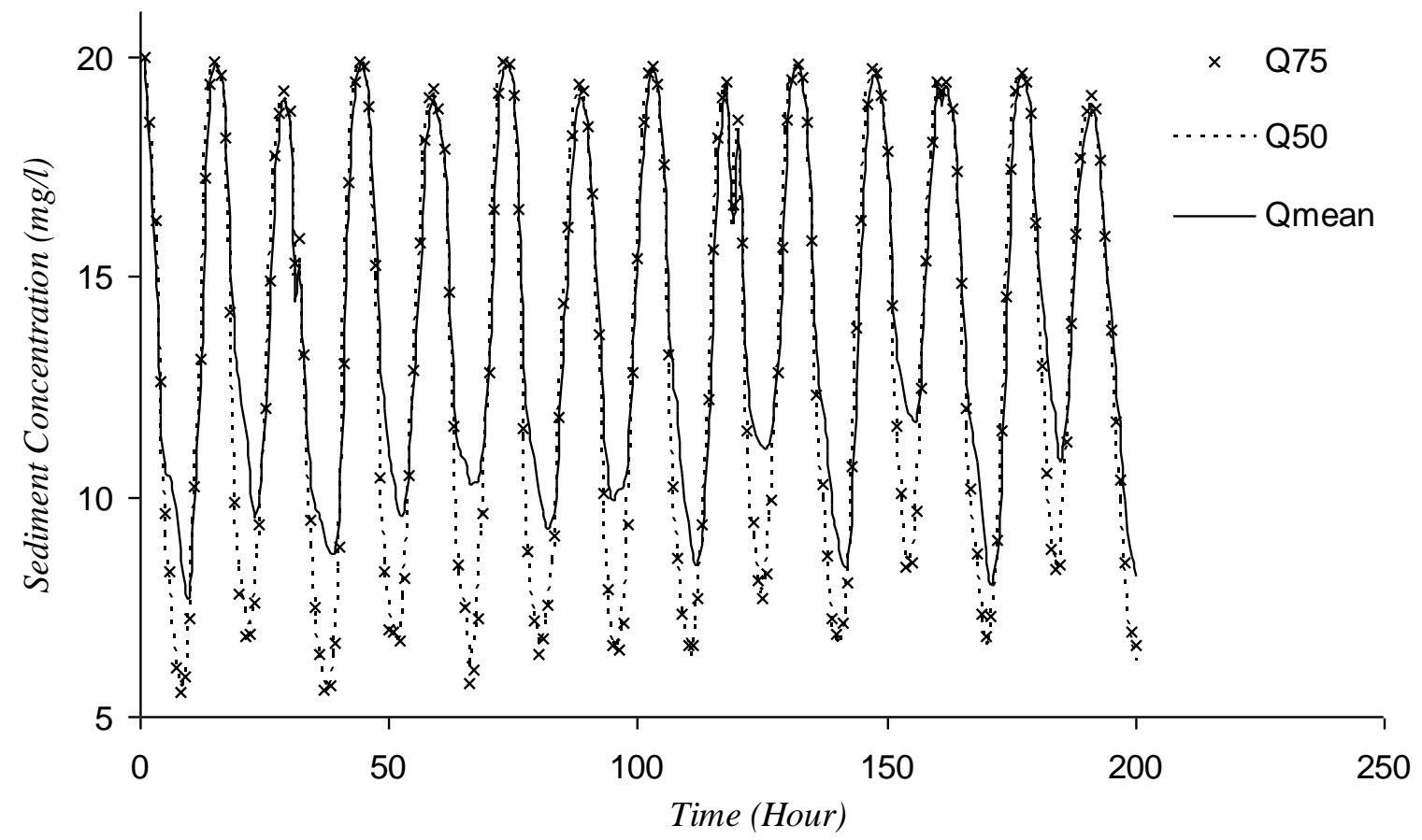

Figure 12. Temporal variations of suspended sediment concentration at Kuan-Du station under various hydrological conditions. Time starts from 00.00 15 March 1994. 


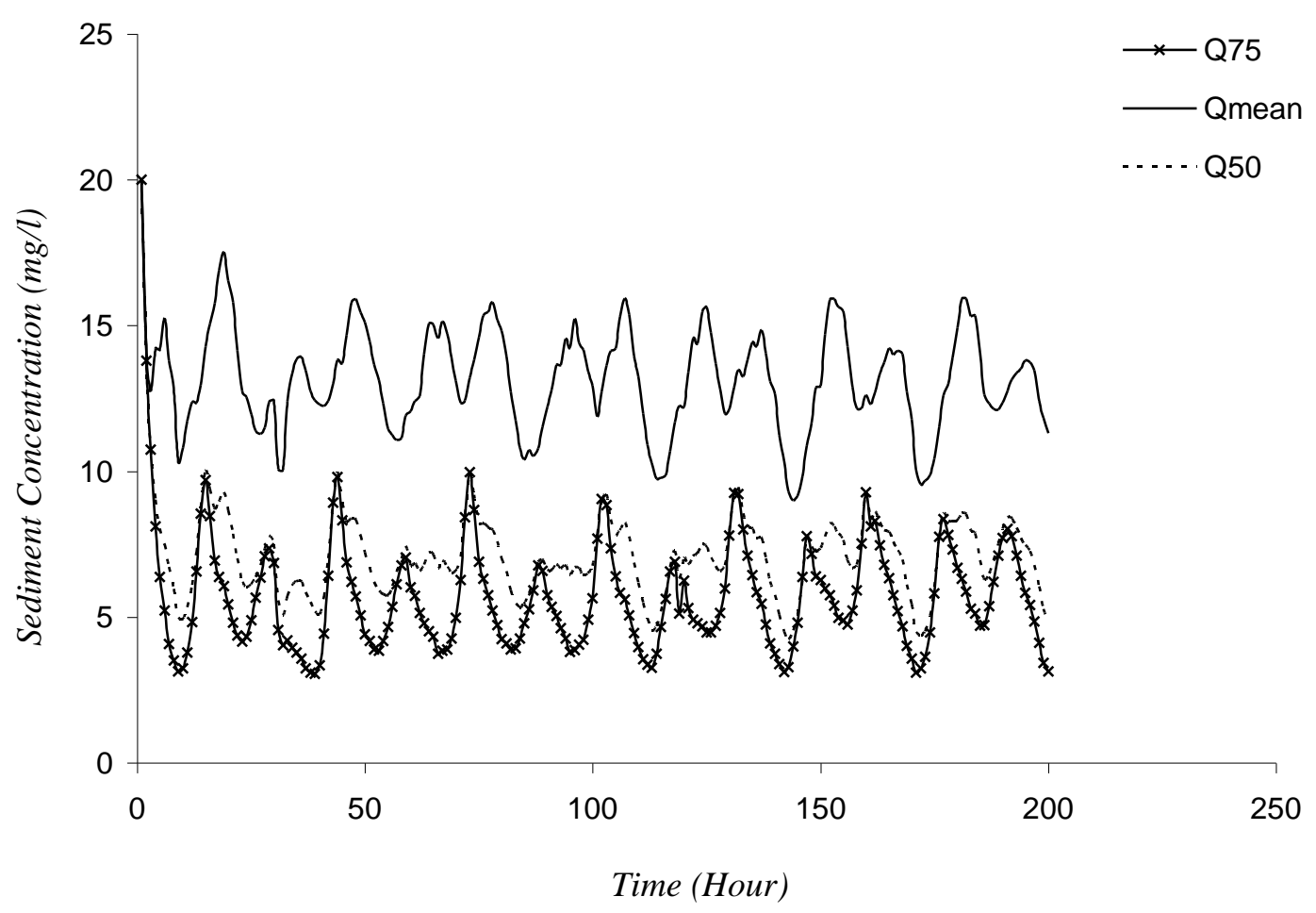

Figure 13. Temporal variations of suspended sediment concentration at Chrong-Yang station under various hydrological conditions. Time starts from 00.0015 March 1994. 


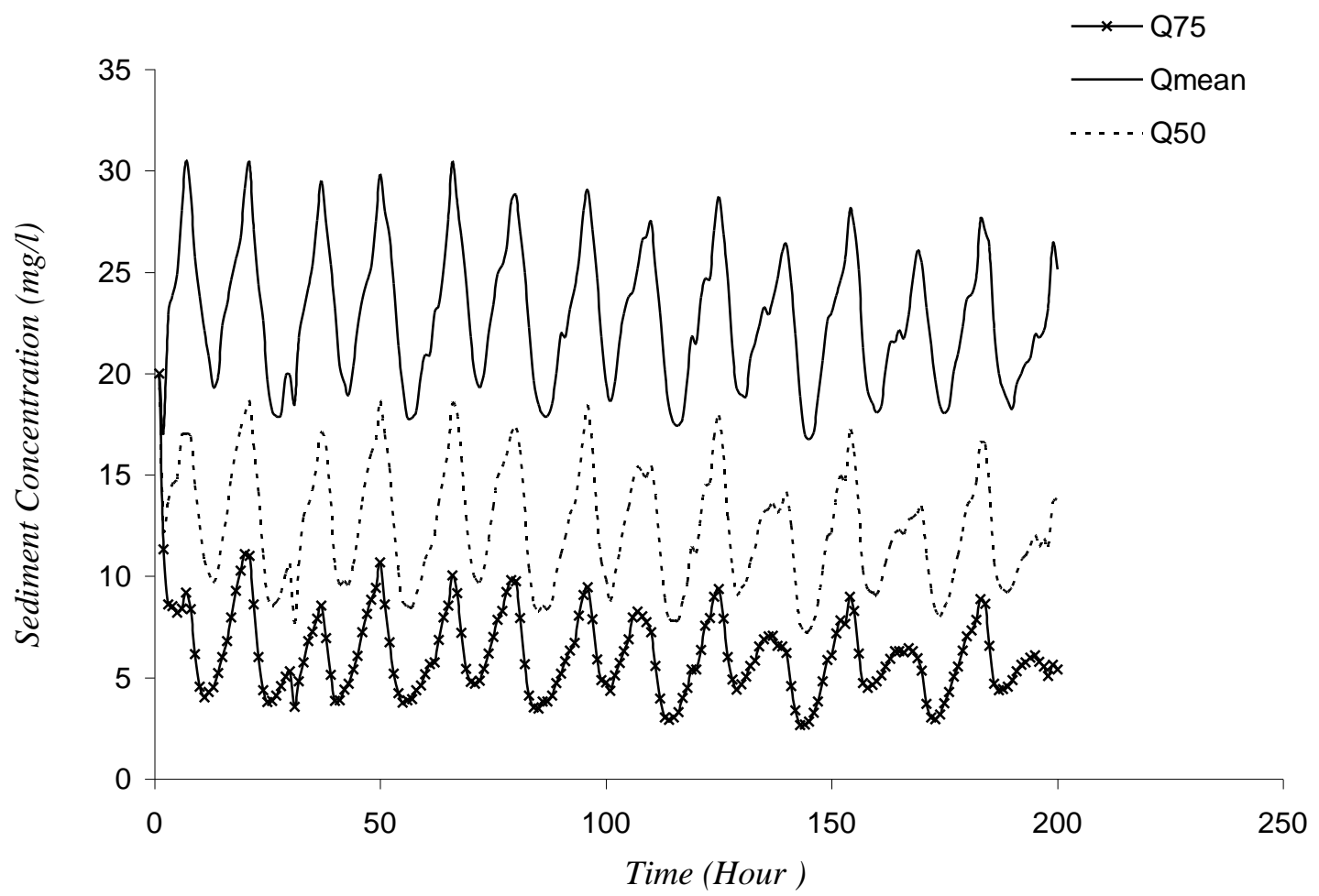

Figure 14. Temporal variations of sediment concentration at Km 19.735 of Tahan Stream under various hydrological conditions. 